\title{
CLINICAL AND COLONOSCOPIC PROFILE OF ISOLATED COLONIC TUBERCULOSIS AT A TERTIARY CARE HOSPITAL IN NORTH INDIA
}

\author{
Vijant Singh Chandail ${ }^{1}$, Vinu Jamwal ${ }^{2}$ \\ ${ }_{1}^{1}$ Lecturer, PG Department of Medicine, Government Medical College, Jammu. \\ ${ }^{2}$ Associate Professor, PG Department of Medicine, Acharya Shree Chander College of Medical Sciences, ASCOMS, Jammu.
}

ABSTRACT
BACKGROUND
Tuberculosis (TB) is one of the oldest diseases known to affect humans and a major cause of death worldwide. According to
World Health Organization, incidence of TB is approximately 9.4 million cases per year, of which 1.98 million cases are from India
and close to 500,000 per year die of the disease in India. It has been estimated that 2-3\% of patients with abdominal TB have isolated
colonic involvement. The diagnosis of intestinal TB is a challenge for physicians due to its diverse clinical manifestations that mimic
other infectious diseases, autoimmune, and neoplastic disorders and therefore, a high index of suspicion is essential to reach the
correct diagnosis.

\section{MATERIALS AND METHODS}

This was a retrospective analysis of colonoscopic findings of patients with isolated colonic tuberculosis who presented between April 2015 - July 2016. All the patients above 18 years of age with suspected diagnosis of intestinal tuberculosis were included in the study. Patients with ulcerative colitis, Crohn's disease, microscopic colitis and indeterminate colitis or carcinoma colon, HIV positive patients were excluded from the study. These patients were taken up for colonoscopy and distal ileoscopy after proper preparation. The findings observed in any part of the colon with particular reference of any aphthous ulcers, granularity, deep ulcers, nodules, polypoidal lesions and luminal narrowings were recorded. A confirmed diagnosis of isolated colonic tuberculosis was made when there were caseating granulomas and or acid fast bacilli on biopsy samples. A suspected diagnosis was made when there was clinical suspicion, with family history of colonic tuberculosis, biopsy showing noncaseating granulomas with chronic inflammation and response to antitubercular therapy. Those patients who had confirmed or suspected diagnosis of isolated colonic tuberculosis were started on antitubercular therapy for a period of 6 months.

\section{RESULTS}

The data of a total of 43 patients was retrieved from the records for this study. Out of these 43 patients, 6 patients were lost to followup. A total of 3 patients did not respond to the antitubercular treatment and were subsequently diagnosed as Crohn's disease on further evaluation. Finally, a total of 34 patients were evaluated in this study, out of which 22 were males and 12 were females. The minimum age in all these patients was 18 years with a maximum age of 79 years. The most common symptom of presentation was pain abdomen (91.17\%) followed by anorexia (88.23\%), Fever (73.52\%), weight loss (70.58\%), chronic diarrhoea (52.94\%), constipation (26.47\%) patients, mass abdomen $(20.58 \%)$ and bleeding per rectum $(14.70 \%)$ of patients. The colonoscopic findings were aphthous ulcers in 18 (52.94\%), deep ulcers in 16 (47.05\%), nodules in 19 (55.88\%), luminal narrowing in 8 (23.52\%) and polypoidal lesions in $5(14.70 \%)$ of patients. The commonest site involved in our patients with isolated colonic tuberculosis was ileocecal valve with caecum in 29 (84.29\%) of patients, followed by isolated ascending colonic involvement in 5 patients and overall in $22(64.70 \%)$ of patients. Other sites of involvement were almost equal in other parts of colon like transverse colon in 19 (55.88\%), descending colon $18(52.94 \%)$ and rectosigmoid region in 18 (52.94\%) and all these patients had ileocecal valve and/or caecal involvement.

\section{CONCLUSION}

Isolated colonic tuberculosis (TB) is rare, and the symptoms are nonspecific making early diagnosis and management difficult. The clinical presentations are variable and the distinction from other conditions of the colon, especially Crohn's disease and cancer needs to be done.

\section{KEYWORDS}

Tuberculosis, Colonoscopy, Histopathology, Antitubercular Treatment.

HOW TO CITE THIS ARTICLE: Chandail VS, Jamwal V. Clinical and colonoscopic profile of isolated colonic tuberculosis at a tertiary care hospital in North India. J. Evolution Med. Dent. Sci. 2016;5(83):6193-6198, DOI: 10.14260/Jemds/2016/1399

Financial or Other, Competing Interest: None

Submission 29-08-2016, Peer Review 05-10-2016,

Acceptance 11-10-2016, Published 15-10-2016.

Corresponding Author:

Dr. Vinu Jamwal,

Associate Professor

PG Department of Medicine,

Acharya Shree Chander College of Medical Sciences,

ASCOMS, Jammu.

E-mail: vinujamwal@yahoo.co.in

DOI: $10.14260 /$ jemds/2016/1399

(c) $($ ) $\$$

\section{BACKGROUND}

Tuberculosis (TB) is a major cause of death worldwide.(1) Onethird of the world's population is infected with tuberculosis (TB), with intestinal TB representing the sixth most common presentation of extrapulmonary TB.(2) According to a World Health Organization, incidence of TB is approximately 9.4 million cases per year, of which 1.98 million cases are from India.(3) and close to 500,000 per year die of the disease in India.(4) Abdominal tuberculosis (TB) is not uncommon in the developing world, but isolated colonic TB is rare. Only 2-3\% of patients with abdominal TB have isolated colonic involvement.(5) 
The diagnosis of intestinal TB is a challenge, due to its diverse clinical manifestations that mimic other infectious diseases, autoimmune, and neoplastic disorders. Therefore, a high index of suspicion is essential to reach the correct diagnosis. The terminal ileum is the most frequently affected gastrointestinal part. This is attributed to the high prevalence of lymphoid tissue in the terminal ileum and a longer contact time of luminal contents with the small bowel. Ulcerations and luminal narrowing are the predominant lesions found in this region of the small bowel. Multiple several small case series have described isolated colonic TB.(5-15) TB is one of the most common diseases infecting the HIV infected persons worldwide due to lower immune levels.

In certain urban settings in some African countries, the rate of HIV infection among TB patients has reached to 70 $80 \%$.(1) Both the incidence and severity of abdominal tuberculosis are expected to increase with increasing incidence of HIV infection. The postulated mechanisms by which the tubercle bacilli reach the gastrointestinal tract are: (i) haematogenous spread from the primary lung focus in childhood, with later reactivation once the immune system is compromised. (ii) ingestion of bacilli in sputum from active pulmonary focus; (iii) direct spread from adjacent organs; and (iv) and through lymph channels from infected nodes.(16) The various pathological lesions of intestinal TB are transverse ulcers, fibrosis, thickening and stricturing of the bowel wall, enlarged and matted mesenteric lymph nodes, omental thickening, and peritoneal tubercles.(1)

\section{MATERIALS AND METHODS}

This was a retrospective analysis of colonoscopic findings of patients with isolated colonic tuberculosis who presented between April 2015 - July 2016. The study design was approved by the Institute's Ethical Committee. A written informed consent was taken from all the patients included in the study. All the patients above 18 years of age with suspected diagnosis of intestinal tuberculosis were included in the study. Patients with ulcerative colitis, Crohn's disease, microscopic colitis and indeterminate colitis or carcinoma colon, HIV positive patients were excluded from the study. All the patients who were included in the study were subjected to details demographic analysis, followed by a detailed history and clinical examination. All the patients were subjected to ultrasonography abdomen to look for any evidence of abdominal lymphadenopathy and if that was seen then those patients were subjected to CECT abdomen to look for any mural thickening of the right side of colon with mesenteric or retroperitoneal lymphadenopathy.

These patients were taken up for colonoscopy and distal ileoscopy after proper preparation of the colon with polyethylene glycol with 2 litres of water, at least 6 hours before the procedures. Colonoscopy was performed by a single gastroenterologist who was blinded to the radiological findings. The colonoscopy was performed under conscious sedation (Inj. Midazolam 2-3 mL IV), in the left lateral position using the Fujinon 2200 processor and colonoscope. The findings observed in any part of the colon with particular reference of any aphthous ulcers, granularity, deep ulcers, nodules, polypoidal lesions and luminal narrowings were recorded. Multiple biopsies were taken from the edge of the ulcers and not from the base, as that would contain most of the times necrotic tissue. The biopsy samples were stained with haematoxylin/eosin and Ziehl-Neelsen stains. Those patients who were having any lesions in the caecum with terminal ileal ulcers were excluded from the study as they would not fit into isolated colonic tuberculosis, where as those with ileocecal valve and caecal involvement with normal terminal ileum were included. A confirmed diagnosis of isolated colonic tuberculosis was made when there were caseating granulomas and or acid fast bacilli on biopsy samples. A suspected diagnosis was made when there was clinical suspicion, with family history of colonic tuberculosis, biopsy showing noncaseating granulomas with chronic inflammation and response to antitubercular therapy. Those patients who had confirmed or suspected diagnosis of isolated colonic tuberculosis were started on antitubercular therapy in the form of 2 months of intensive phase (4 drugs - isoniazid, rifampicin, ethambutol, pyrazinamide) followed by 4 months of continuation phase ( 2 drugs - isoniazid, rifampicin) as per the revised national tuberculosis programme guidelines.

The patients were followed up at regular intervals to access the response to therapy and a repeat colonoscopy was done after 6 months of antitubercular therapy. The therapy was stopped if there was complete healing of the lesions. In case of partial healing, the antitubercular therapy was extended for a period of 3 more months.

\section{RESULTS}

The data of a total of 43 patients was retrieved from the records for this study. Out of these 43 patients, 6 patients were lost to followup. A total of 3 patients did not respond to the antitubercular treatment and were subsequently diagnosed as Crohn's disease on further evaluation. Finally, a total of 34 patients were evaluated in this study, out of which 22 were males and 12 were females. The minimum age in all these patients was 18 years with a maximum age of 79 years. The clinical presentation of all the patients is described in table 1. The most common symptom of presentation was pain abdomen (91.17\%) followed by anorexia (88.23\%). Fever was the presenting symptom in $73.52 \%$ of patients, whereas weight loss was seen in $70.58 \%$ of patients. Chronic diarrhoea was seen in $52.94 \%$ of the patients whereas $26.47 \%$ patients presented with constipation. Mass abdomen was seen in $20.58 \%$ of patients and bleeding per rectum was the presenting symptom in $14.70 \%$ patients. On clinical examination, the various signs seen in these patients were (table 2) pallor in $76.47 \%$, low grade fever in $73.52 \%$, diffuse abdominal tenderness in $55.88 \%$, abdominal mass in $20.58 \%$ and peripheral lymphadenopathy in $8.82 \%$ of patients.

The routine baseline investigations in the form of complete blood count, liver function tests, renal function tests, blood sugar fasting and coagulation profile were done in all these patients and nothing worth mentioning was noted in these investigations. Abnormal x-ray chest in the form of upper lobe soft infiltrates was seen in 9 patients. Abdominal ultrasonography revealed mesenteric or retroperitoneal lymphadenopathy in 29 patients. Contrast enhanced computerised tomography (CECT Abdomen) revealed mesenteric and retroperitoneal lymphadenopathy in 32 patients, in addition to other findings of mural thickening of the right colon, fat stranding and pericolonic lymphadenopathy. 


\section{Colonoscopic Findings}

The commonest colonoscopic finding in our patients was deformed ileocecal valve with right colonic ulcers in $29(85.29 \%)$ patients with normal terminal ileum. Other colonoscopic findings (Table 3) were aphthous ulcers in 18 (52.94\%) (Images 1 \& 2), deep ulcers in 16 (47.05\%) (Image $3)$, nodules in 19 (55.88\%) (Image 4), luminal narrowing in 8 (23.52\%) (Image 5) and polypoidal lesions in 5 (14.70\%) patients (Image 6). The commonest site involved in our patients with isolated colonic tuberculosis was ileocecal valve with caecum in 29 (84.29\%) of patients, followed by isolated ascending colonic involvement in 5 patients and overall in 22 (64.70\%) of patients (Table 4). Other sites of involvement were almost equal in other parts of colon like transverse colon in 19 (55.88\%), descending colon 18 (52.94\%) and rectosigmoid region in $18(52.94 \%)$ and all these patients had ileocecal valve and/or caecal involvement. Skip lesions were seen in 12 (35.29\%) of the patients in our study. The biopsy samples were stained with haematoxylin/eosin and ZiehlNeelsen stains and presence of caseating granulomas with acid fast bacilli was seen in only 9 patients documenting these to be having confirmed diagnosis of isolated colonic tuberculosis. Whereas a total of 25 patients had noncaseating granulomas with epithelioid cells, Langerhans giant cells and chronic inflammatory infiltrate, with/without family history of tuberculosis.

All the patients were started on antitubercular therapy and a total of $21(61.76 \%)$ responded to 6 months of therapy and followup colonoscopy at 6 months revealed complete healing of the lesions. Further $6(17.64 \%)$ more patients responded to extending the therapy to a total of 9 months as they had partial healing of the lesions after 6 months of therapy. 7 (20.58\%) patients out of 34 patients did not respond to therapy as most of these patients had presented with abdominal mass and during the treatment period only they had presented with features of subacute intestinal obstruction and had to be subjected to surgical resection of the colon.

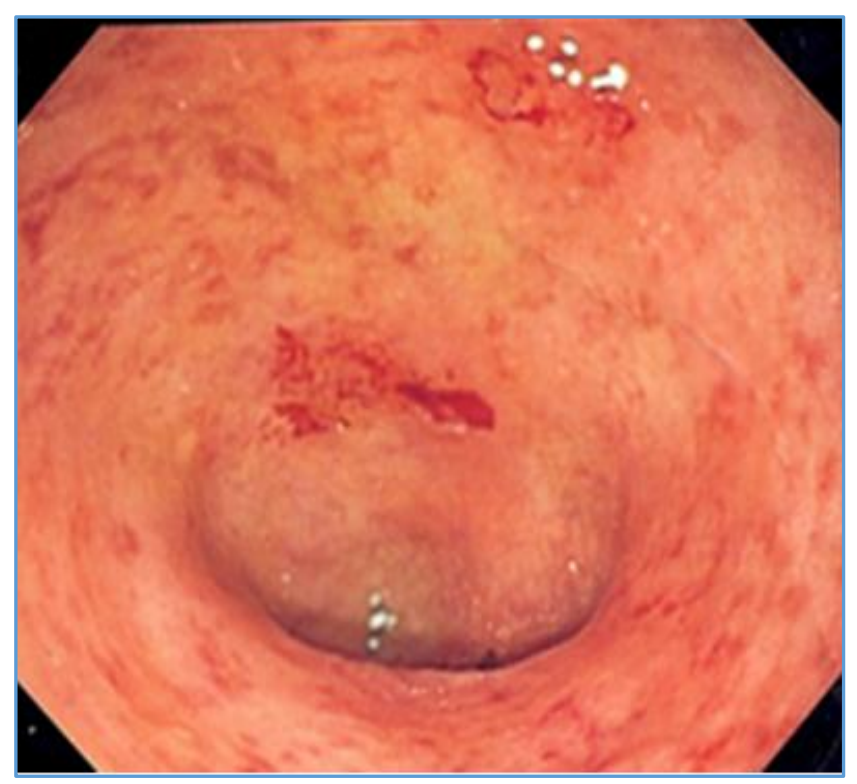

Image 1: Multiple Aphthous Ulcers in Colon

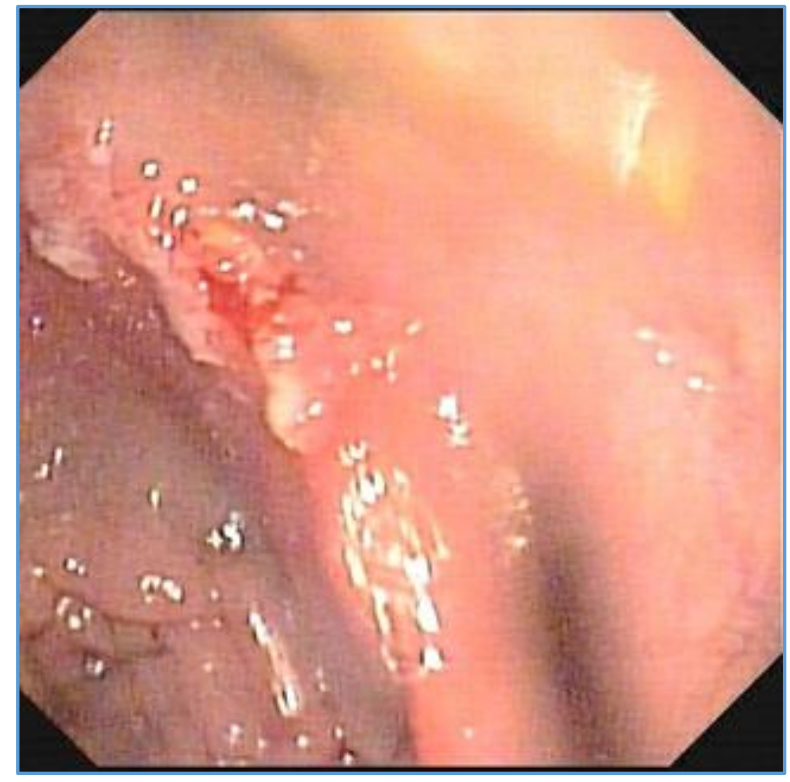

Image 2: Multiple Aphthous Ulcers on Colonoscopy

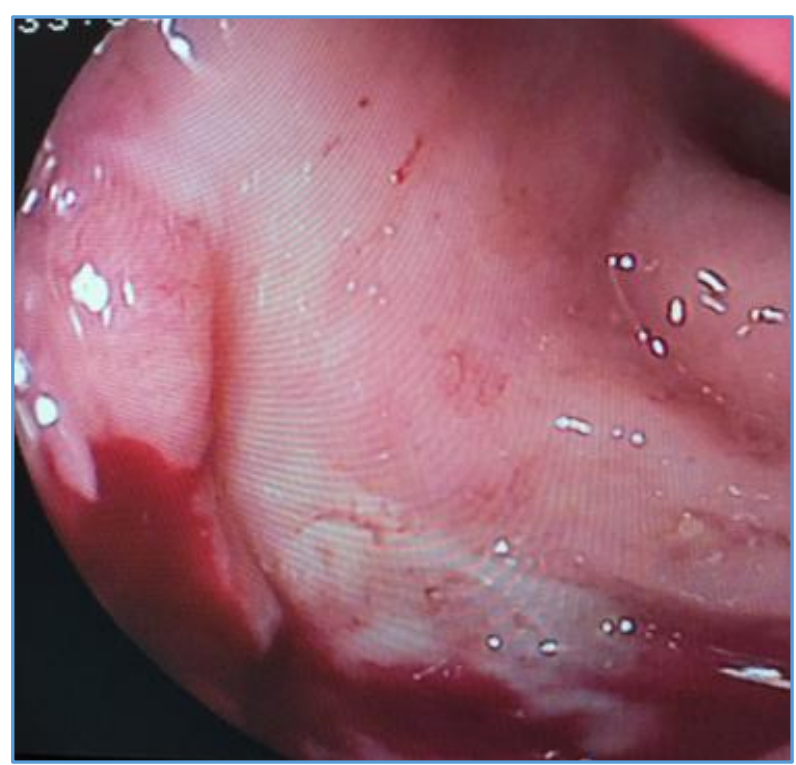

Image 3: Deep Ulcers on Colonoscopy

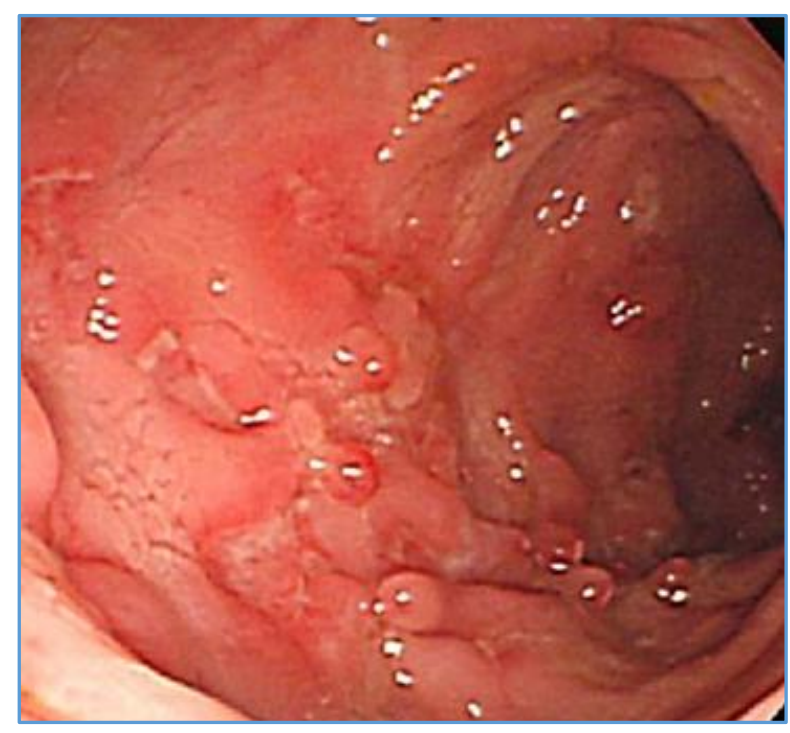

Image 4: Nodularity on Colonoscopy 


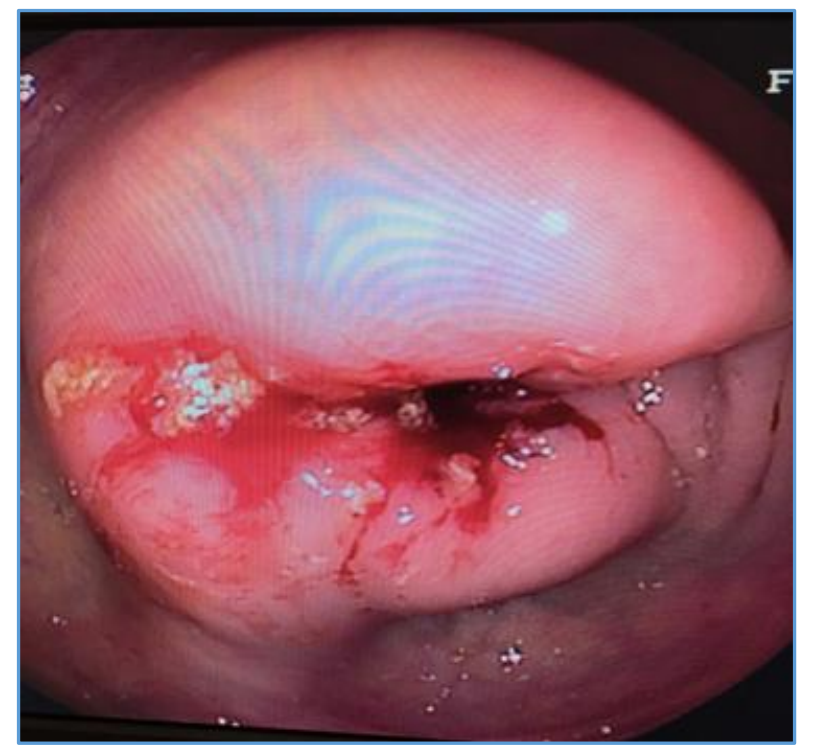

Image 5: Polypoidal Lesion with Luminal Narrowing

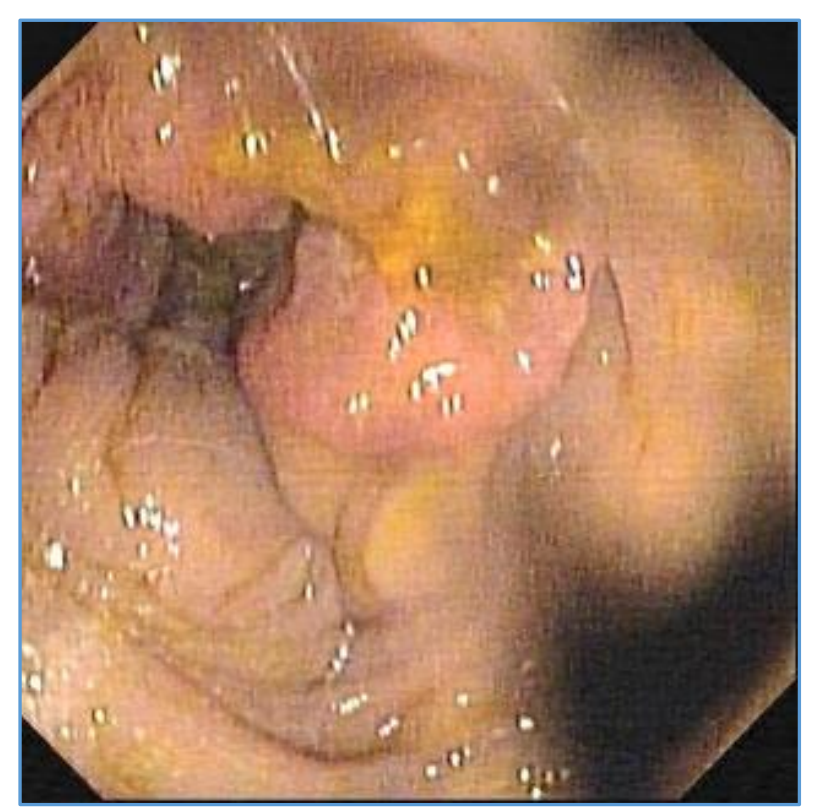

Image 6: Polypoidal Lesion with Luminal Narrowing

\begin{tabular}{|c|c|}
\hline Pain abdomen & $31(91.17 \%)$ \\
\hline Anorexia & $30(88.23 \%)$ \\
\hline Fever & $25(73.52 \%)$ \\
\hline Weight loss & $24(70.58 \%)$ \\
\hline Diarrhoea & $18(52.94 \%)$ \\
\hline Constipation & $9(26.47 \%)$ \\
\hline Altered bowels & $7(20.58 \%)$ \\
\hline Abdominal mass & $7(20.58 \%)$ \\
\hline Bleeding P/R & $5(14.70 \%)$ \\
\hline $\begin{array}{c}\text { Table 1: Clinical Presentation of Symptoms in Patients } \\
\text { with Isolated Colonic Tuberculosis }\end{array}$ \\
\hline
\end{tabular}

\begin{tabular}{|c|c|}
\hline Pallor & $26(76.47 \%)$ \\
\hline Fever & $25(73.52 \%)$ \\
\hline Abdominal Tenderness & $19(55.88 \%)$ \\
\hline Abdominal Mass & $7(20.58 \%)$ \\
\hline Peripheral Lymphadenopathy & $3(8.82 \%)$ \\
\hline $\begin{array}{c}\text { Table 2: Clinical Signs in Patients with } \\
\text { Isolated Colonic Tuberculosis }\end{array}$ \\
\hline
\end{tabular}

\begin{tabular}{|c|c|}
\hline Deformed IC Valve with ulcers in caecum & $29(85.29 \%)$ \\
\hline Aphthous ulcers & $18(52.94 \%)$ \\
\hline Deep ulcers & $16(47.05 \%)$ \\
\hline Nodules & $19(55.88 \%)$ \\
\hline Luminal narrowings & $8(23.52 \%)$ \\
\hline Polypoidal lesions & $5(14.70 \%)$ \\
\hline $\begin{array}{c}\text { Table 3: Colonoscopic Findings in Patients } \\
\text { with isolated Colonic Tuberculosis }\end{array}$ \\
\hline
\end{tabular}

\begin{tabular}{|c|c|}
\hline IC valve \& Caecum & $29(85.29 \%)$ \\
\hline Ascending Colon & $22(64.70 \%)$ \\
\hline Transverse Colon & $19(55.88 \%)$ \\
\hline Descending Colon & $18(52.94 \%)$ \\
\hline Rectosigmoid & $18(52.94 \%)$ \\
\hline \multicolumn{2}{|c|}{ Table 4: Commonest Sites of Colonic Involvement } \\
\hline
\end{tabular}

\section{DISCUSSION}

The WHO estimated 9 million new cases of TB occurred worldwide in 2013, 95\% of them in developing countries of Asia (5 million), Africa (2.6 million), the Middle East (0.7 million). Of this $13 \%$ (1.1 million) were associated with HIV infection. Furthermore, an estimated 480,000 cases of multidrug resistant TB (MDR-TB) a form of disease caused by bacilli resistant to isoniazid and rifampicin occurred in 2013.(1) About 0.4 million people in India are co-infected with HIV and tuberculosis.(17) Gastrointestinal TB account for 10-15 per cent of TB and this may increase up to 50 per cent of patients with AIDS. Gastrointestinal TB is the sixth most frequent form of extra-pulmonary site, after lymphatic, genitourinary, bone and joint, miliary and meningeal tuberculosis. ${ }^{(18)}$

In India, the organism isolated from all intestinal lesions has been Mycobacterium tuberculosis and not M. bovis. $(19,20)$ Although any portion of the gastrointestinal tract may be affected, the terminal ileum is most commonly involved because of the relatively longer contact time of intestinal contents with the mucosa and abundant lymphoid tissue. The frequency of bowel involvement declines as one proceeds both proximally and distally from the ileocaecal region.(16)

Isolated colonic tuberculosis (TB) is rare, and the symptoms are nonspecific making early diagnosis and management difficult. The presentation features are variable and the distinction from other conditions of the colon, especially Crohn's disease and cancer needs to be done.

In this study, we diagnosed patients of isolated colonic tuberculosis with colonoscopic findings and histopathology. The most common symptom in our study was abdominal pain, seen in $91 \%$ of patients. This is similar to previous published series. ${ }^{21,22)}$ The pain can involve any part of the abdomen but more common in lower abdomen. Abdominal pain can be colicky in nature suggesting presence of intestinal obstruction or it can present as continuous dull abdominal pain which indicates peritoneal inflammation. Weight loss is also an important symptom and was seen in $70 \%$ of our patients which is in comparison to the published series.(23) The Malabsorption secondary to small bacterial overgrowth. $(24,25)$ increased bile salt loses from ileum. (26) and anorexia all contributes to weight loss. In our series, bleeding per rectum was seen in $14 \%$ patients. The bleeding was minor and did not require surgical intervention. Mukewar et al observed bleeding per rectum in $20 \%$ of patients. (27) and Singh et al reported rectal bleeding in $31 \%$ of patients with colonic TB and it was massive in $13 \%$ cases.(28) In our study, the commonest site of colonic involvement was IC valve, caecum 
and ascending colon. In Bhansali's series, including 196 patients with gastrointestinal tuberculosis, ileum was involved in 102 and caecum in 100 patients. (29) In another study by Prakash et al, of the 300 patients, ileocaecal involvement was present in $162(\sim 50 \%)$.(30)

Chest x-ray abnormalities in our series are seen in 9 (26.47\%) patients. Sharma et al studied 70 cases of abdominal tuberculosis and found evidence of active or healed lesions on chest x-ray in 22 (46\%).(31), whereas Tandon et al found chest $\mathrm{x}$-ray to be positive in only 25 percent of their patients.(32)

The predominant lesion observed on colonoscopy in our study was ulceration in caecum (85\%), followed by nodules (55\%) and polypoidal growth (14\%). In Mukewar et al series, ulcers (88\%), nodules (50\%), polypoidal growth $(10 \%)$ were seen.(27) Misra SP et al documented ulcers (92\%) and polypoidal growth (6\%).(33). The hallmark of diagnosis is demonstration of caseating granuloma on histological examination, noncaseating granulomas may be seen due to low virulence of the organism or high resistance of the host or due to previous antitubercular therapy.(34) Granulomas have been reported in only $40 \%$ of patients with abdominal tuberculosis. These granulomas in tuberculosis are of variable size and characteristically tend to be confluent, in contrast to those in Crohn's disease. Tubercular ulcers are relatively superficial and usually do not penetrate beyond the muscularis.(35)

In the present study, on histology examination of the colonic biopsy specimen, 9 patients (26\%) had caseating granulomas with acid fast bacilli and 25 biopsy specimen had shown noncaseating granuloma with epithelioid cells, Langerhans giant cells and chronic inflammatory infiltrates. The majority of patients in whom we could document caseating granulomas where resected colonic specimens who underwent surgery due to intestinal obstruction as they had not responded to antitubercular therapy.

In this series, 3 patients did not respond to the antitubercular treatment and on subsequent evaluation were diagnosed as Crohn's disease. Colonoscopy differentiation between Tuberculosis of the colon and Crohn's disease can be difficult. (36) The changes caused by acute inflammation of the colonic mucosa namely oedematous mucosa, mucosal ulceration and nodularity, luminal narrowing, strictures and pseudopolyps can occur in both conditions.(37)

All patients received conventional antitubercular therapy for at least 6 months including initial 2 months of rifampicin, isoniazid, pyrazinamide and ethambutol, followed by 4 months of isoniazid and rifampicin as per the revised criteria for national tuberculosis control programme. $61 \%$ of our patients responded to 6 months course of ATT. In $17 \%$, we had to extend ATT to 9 months for complete healing of the lesions. In 6 patients (20\%) who had large polypoidal lesions, while on ATT therapy, developed features of subacute intestinal obstruction and were subjected to surgical resection. Anand et al reported clinical and radiological resolution of tuberculous strictures with drug therapy even in patients with subacute intestinal obstruction. They treated 39 patients with obstructive symptoms using medical therapy. At the end of one year, 91 percent showed clinical improvement.(38) The high incidence of non-response to ATT and surgical resection in our study could have been because of large polypoidal lesions in these patients, and they presented with intestinal obstruction.

\section{SUMMARY}

Tuberculosis is a life threatening disease and India is the leading country, which is around $26 \%$ of the world TB cases, followed by China and South Africa.

Isolated colonic tuberculosis (TB) is rare, and the symptoms are nonspecific making differentiation from other conditions, especially Crohn's disease and cancer difficult. A high degree of clinical suspicion is required to make the diagnosis of TB in those sites which are not commonly involved. The colonic tuberculosis is generally managed with medical therapy with antitubercular drugs for a period of 6 months and surgical therapy is indicated only in emergency cases for the patients presenting with intestinal obstructions that were not relieved conservatively.

\section{REFERENCES}

1. Raviglione MC. Tuberculosis. $19^{\text {th }}$ ed. In: Kasper DL, Fauci AS, Hauser SL, et al. (eds) Harrison principles of internal medicine edition. McGraw Hill Vol. 2:P 1103-21.

2. Donoghue HD, Holton J. Intestinal tuberculosis. Current Opinion in Investigational Drugs 2009;22(5):490-6.

3. WHO. Global Tuberculosis Control-Epidemiology, Strategy, Financing. WHO 2009:411. (WHO/HTM/TB/2009).

4. Khatri GR, Frieden TR. Controlling tuberculosis in India. N Engl J Med 2002;347(18):1420-5.

5. Bhargava DK, Kushwaha AK, Dasarathy S, et al. Endoscopic diagnosis of segmental colonic tuberculosis. Gastrointest Endosc 1992;38(5):571-4.

6. Alvares JF, Devarbhavi H, Makhija P, et al. Clinical, colonoscopic, and histological profile of colonic tuberculosis in a tertiary hospital. Endoscopy 2005;37(4):351-6.

7. Bhargava DK, Tandon HD, Chawla TC, et al. Diagnosis of ileocecal and colonic tuberculosis by colonoscopy. Gastrointest Endosc 1985;31(2):68-70.

8. Das HS, Rathi P, Sawant P, et al. Colonic tuberculosis: colonoscopic appearance and clinico-pathologic analysis. J Assoc Physicians India 2000;48(7):708-10.

9. Medina E, Orti E, Tome A, et al. Segmental tuberculosis of the colon diagnosed by colonoscopy. Endoscopy 1990;22(4):188-90.

10. Morgante PE, Gandara MA, Sterle E. The endoscopic diagnosis of colonic tuberculosis. Gastrointest Endosc 1989;35(2):115-8.

11. Nagi B, Kochhar R, Bhasin DK, et al. Colorectal tuberculosis. Eur Radiol 2003;13(8):1907-12.

12. Namisaki T, Yoshiji H, Fujimoto $M$, et al. Two cases of colonic tuberculosis presenting with massive melena. Int J Clin Pract 2004;58(12):1162-4.

13. Pulimood AB, Peter S, Ramakrishna B, et al. Segmental colonoscopic biopsies in the differentiation of ileocolic tuberculosis from Crohn's disease. J Gastroenterol Hepatol 2005;20(5):688-96.

14. Shah S, Thomas V, Mathan M, et al. Colonoscopic study of 50 patients with colonic tuberculosis. Gut 1992;33(3):347-51.

15. Saenz VE, Magro MHP, Alvarez-Tostado FFJ, et al. Colonic tuberculosis. Dig Dis Sci 2002;47(9):2045-8.

16. Sharma MP, Vikram B. Abdominal tuberculosis. Indian J Med Res 2004;120:305-15. 
17. Rathi PM, Amarapurakar DN, Parikh SS, et al. Impact of human immunodeficiency virus infection on abdominal tuberculosis in western India. J Clin Gastroenterol 1997; 24(1):43-8.

18. Paustian FF. Tuberculosis of the intestine. $2^{\text {nd }}$ ed. In: Bockus HL, (edr). Gastroenterology, vol.11. Philadelphia: WB Saunders Co 1964:311.

19. Wig KL, Chitkara NK, Gupta SP, et al. Ileocecal tuberculosis with particular reference to isolation of mycobacterium tuberculosis. With a note on its relation to regional ileitis (Crohn's disease). Am Rev Respir Dis 1961;84:169-78.

20. Vij JC, Malhotra V, Choudhary V, et al. A clinicopathological study of abdominal tuberculosis. Indian $\mathrm{J}$ Tuberc 1992;39:213-20.

21. Arya TVS, Jain AK, Kumar M, et al. Colonic tuberculosis: a clinical and colonoscopic profile. Indian J Gastroenterol 1994;13(Suppl)A116.

22. Bhargava DK, Tandon HD, Chawla TC, et al. Diagnosis of ileocecal and colonic tuberculosis by colonoscopy. Gastrointest Endosc 1985;31(2):68-70.

23. Anand SS. Hypertrophic ileocaecal tuberculosis in India with a record of fifty hemicolectomies. Ann R Coll Surg 1956;19(4):205-22.

24. Tandon RK, Bansal R, Kapur BML, et al. A study of malabsorption in intestinal tuberculosis: stagnant loop syndrome. Am J Clin Nutr 1980;33(2):244-50.

25. Pimparker BD, Dhonde UM. Intestinal tuberculosis: gastrointestinal absorption studies. J Assoc Physicians India 1974;22(3):219-28.

26. Desai HG, Zaveri MP, Antia FP. Bile salt metabolism in intestinal tuberculosis increased glycine: taurine ratio of conjugated bile salts. Indian J Med Res 1975;63(12): 176773.

27. Saurav M, Shrikant M, Ravi R. Colon tuberculosis: endoscopic features and prospective endoscopic follow-up after anti-tuberculosis treatment. Clinical and Translational Gastroentrology 2012;3(10):e24.
28. Singh V, Kumar P, Kamal J, et al. Clinicocolonoscopic profile of colonic tuberculosis. Am J Gastroenterol 1996; 91(3): 565-8.

29. Bhansali SK. Abdominal tuberculosis. Experiences with 300 cases. Am J Gastroenterol 1977;67(4):324-37.

30. Prakash A. Ulcero-constrictive tuberculosis of the bowel. Int Surg 1978;63(5):23-9.

31. Kapoor VK, Chattopadhyay TK, Sharma LK. Radiology of abdominal tuberculosis. Australas Radiol 1988;32(3): 3657.

32. Tandon RK, Sarin SK, Bose SL, et al. A clinico-radiological reappraisal of intestinal tuberculosis-changing profile? Gastroenterol Jpn 1986;21(1):17-22.

33. Misra SP, Vatsala M, Manisha D. Colonic tuberculosis: clinical features, endoscopic appearance and management. J Gastroenterol Hepatol 1999;14(7):723-9.

34. Kapoor VK. Abdominal tuberculosis: the Indian contribution. Indian Journal of Gastroenterology 1998;17:141-7.

35. Tandon HD, Prakash A. Pathology of intestinal tuberculosis and its distinction from Crohn's disease. Gut 1972;13(4):260-9.

36. Ferentzi CV, Sieck JO, Ali MA. Colonoscopic diagnosis and medical treatment of ten patients with colonic tuberculosis. Endoscopy 1988;20:62-5.

37. Kalvaria I, Kottler RE, Marks IN. The role of colonoscopy in the diagnosis of tuberculosis. J Clin Gastroenterol 1988;10(5):516-23.

38. Anand BS, Nanda R, Sachdev GK. Response of tuberculous stricture to antituberculous treatment. Gut 1988;29(1): 62-9. 